\title{
Safety and tolerability of 6-month supplementation with a vitamin D, calcium and leucine-enriched whey protein medical nutrition drink in sarcopenic older adults
}

\author{
Jürgen M. Bauer ${ }^{1} \cdot$ Lucia Mikušová $^{2} \cdot$ Sjors Verlaan $^{3} \cdot$ Ivan Bautmans $^{4} \cdot$ Kirsten Brandt $^{5} \cdot$ Lorenzo M. Donini $^{6}$. \\ Marcello Maggio ${ }^{7}$. Tony Mets ${ }^{4}$. Sander L. J. Wijers ${ }^{2} \cdot$ Jossie A. Garthoff $^{8} \cdot$ Yvette Luiking $^{2} \cdot$ Cornel Sieber $^{9}$. \\ Tommy Cederholm ${ }^{10}$ on behalf of the PROVIDE Consortium
}

Received: 22 November 2019 / Accepted: 17 February 2020 / Published online: 12 March 2020

(c) The Author(s) 2020

\begin{abstract}
Aims Safety and tolerability of prolonged supplementation with a vitamin D, calcium and leucine-enriched whey protein medical nutrition drink (WP-MND) was evaluated in sarcopenic older adults.

Methods A 13-week double-blinded, randomized, isocaloric placebo-controlled trial (PROVIDE study; $n=380$ ) was extended with a voluntary 13-week open-label extension (OLE). OLE participants were randomized to receive daily 1 or 2 servings of WP-MND (21 g protein, $3 \mathrm{~g}$ leucine, $10 \mu \mathrm{g}$ vitD and $500 \mathrm{mg}$ calcium per serving). Gastro-intestinal tolerability, kidney function and serum levels of calcidiol, parathyroid hormone (PTH) and calcium were evaluated at week 0, 13 and 26. Results and discussion In response to the high daily protein intake (median $1.5 ; \mathrm{IQR}: 1.3,1.7 \mathrm{~g} / \mathrm{kg} \mathrm{BW} /$ day), the estimated glomerular filtration rate (eGFR) increased in the test group during the RCT $(p=0.013)$. The same trend was observed for those participants with moderate chronic kidney disease. During OLE no eGFR change was observed in any of the groups. Serum calcidiol and calcium reached a plateau after 13-week WP-MND supplementation. As expected, PTH significantly changed in the opposite direction, decreasing during RCT in the test group (T vs $\mathrm{C}: p<0.001$ ) and during OLE in former control groups. During RCT, 20/366 participants with normal baseline calcidiol reached levels $\geq 100 \mathrm{nmol} / \mathrm{L}$ (T: $n=18 ; \mathrm{C}: n=2)$ and 6 developed albumin-corrected calcium levels $>2.55 \mathrm{mmol} / \mathrm{L}$ (T: $n=3$; C: $n=3$ ), without associated adverse events. Conclusion A 6 months intervention with up to 2 servings of WP-MND did neither result in kidney function deterioration nor symptoms of vitamin $\mathrm{D}$ or calcium toxicity. The product was overall well tolerated.
\end{abstract}

Keywords Nutrition $\cdot$ Safety $\cdot$ Tolerability $\cdot$ Sarcopenia $\cdot$ Whey protein $\cdot$ Vitamin D

Jürgen M. Bauer

Juergen.Bauer@bethanien-heidelberg.de

1 Center for Geriatric Medicine, University Heidelberg, Agaplesion Bethanien Krankenhaus Heidelberg, Heidelberg, Germany

2 Danone Nutricia Research, Nutricia Advanced Medical Nutrition, Utrecht, The Netherlands

3 Department of Internal Medicine, Section of Gerontology and Geriatrics, VU, Amsterdam University Medical Center, Amsterdam, The Netherlands

4 Frailty in Ageing Research Group (FRIA), Vrije Universiteit Brussel (VUB), Brussels, Belgium

5 Human Nutrition Research Centre, School of Agriculture, Food and Rural Development, Newcastle University Institute for Ageing, Newcastle University, Newcastle upon Tyne, UK
6 Department of Experimental Medicine, Section of Medical Pathophysiology, Endocrinology and Human Nutrition, "Sapienza" University of Rome, Rome, Italy

7 Department of Clinical and Experimental Medicine, Section of Geriatrics, University of Parma, Parma, Italy

8 Danone Food Safety Center, Utrecht, The Netherlands

9 Friedrich-Alexander-Universität Erlangen-Nürnberg, Erlangen, Germany

10 Department of Public Health and Caring Sciences/Clinical Nutrition and Metabolism, Department of Geriatric Medicine, Uppsala University Hospital, Uppsala, Sweden 


\section{Introduction}

Sufficient dietary intake of protein, and an adequate vitamin $\mathrm{D}$ and calcium status has been proposed as a way to attenuate age-related loss of muscle and bone [1-8]. This is especially important for frail, sarcopenic and osteoporotic older adults who are at risk of falls, fractures and subsequent hospitalization or institutionalization [9-11]. The European Society for Clinical Nutrition and Metabolism (ESPEN), the European Union Geriatric Medicine Society (EUGMS), and the European Society for Clinical and Economic Aspects of Osteoporosis and Osteoarthritis (ESCEO) recommend a protein intake of 1.0-1.2 g protein/kg bodyweight (BW)/day (d) for healthy older individuals and $1.2-1.5 \mathrm{~g} / \mathrm{kg} \mathrm{BW} /$ day for geriatric patients with acute and/or chronic diseases [7, 9, 12]. The Institute of Medicine in the USA and ESCEO recommend a daily intake of $800 \mathrm{IU}(=20 \mu \mathrm{g})$ vitamin $\mathrm{D}_{3}$ for people of 71 years and older to sustain 25 -hydroxyvitamin $\mathrm{D}$ (calcidiol) levels above $50 \mathrm{nmol} / \mathrm{L}[5,7,13-15]$. Calcidiol is the precursor of the active, but short-lived 1,25-hydroxyvitamin D (calcitriol), and represents an integrated marker of vitamin D status as a result of endogenous synthesis from sun exposure and dietary intake [5]. The recommended daily allowance (RDA) for calcium for people of 71 years and older is $1200 \mathrm{mg} /$ day [5]. Despite the recommendations above, insufficient intake of protein, vitamin $\mathrm{D}$ and calcium is still common in communitydwelling older adults $[16,17]$. This may also partly explain the observed $45 \%$ prevalence of vitamin D deficiency, i.e. calcidiol $<50 \mathrm{nmol} / \mathrm{L}$, in a large cohort of community-dwelling older ( $\geq 65$ years) individuals [18].

Previously, an intervention with a vitamin D, calcium and leucine-enriched whey protein medical nutrition drink was shown to enhance muscle mass and improve lower-extremity function in sarcopenic older adults [19]. To obtain these beneficial effects, two servings of the medical nutrition drink and thereby high amounts of protein (42 g), leucine (6 g), vitamin $\mathrm{D}(40 \mu \mathrm{g})$ and calcium $(1000 \mathrm{mg})$ per day were consumed on top of the regular diet. However, this may cause safety concerns in this vulnerable older target population with regard to kidney function and potential vitamin D or calcium toxicity. Older adults experience kidney function decline with age [20] and those with moderate or severe chronic kidney disease are advised to restrict protein intake and/or have their kidney function monitored on a regular basis [7, 9, 12]. Vitamin D or calcium toxicity related hypercalcemia may facilitate the formation of kidney stones and calcification of soft and vascular tissues, and result in acute symptoms such as nausea, vomiting, increased thirst and depression [21].

The aim of this post-hoc evaluation was to determine the effect of 6 months supplementation with a vitamin D, calcium and leucine-enriched whey protein medical nutrition drink (WP-MND) on kidney function and on vitamin D, PTH and calcium levels in sarcopenic older adults. For this purpose, we extended the 13-week randomized placebocontrolled trial [19], with a subsequent voluntary 13-week open-label study period with WP-MND supplementation in both the former test and control groups. In addition, general safety was evaluated with parameters of liver function and registration of adverse events and tolerability was evaluated by a questionnaire addressing symptoms of gastrointestinal discomfort.

\section{Methods}

\section{Participants}

As described in detail before $[19,22]$, participants were recruited from 18 study centers in 6 European countries. Older adults ( $\geq 65$ years) were eligible when they suffered from sarcopenia, defined as low skeletal muscle mass index (SMI) combined with mild to moderate limitations in physical performance (for definitions applied see reference [19]). People with liver or kidney failure were excluded from participation. Known kidney failure was defined in the published protocol as estimated glomerular filtration rate (eGFR) below $30 \mathrm{~mL} / \mathrm{min} / 1.73 \mathrm{~m}^{2}$, what means that participants with moderate chronic kidney disease (eGFR between 30 and 60) were eligible for participation in the study. For this group, Bauer et al. recommend that they adhere to general protein recommendations for older people (1.0-1.5 g protein/kg BW/day), but have their GFR monitored twice a year [9]. Other exclusion criteria relevant were: (a) intake of a high protein diet 3 months before start of or during the study, (b) intake of a protein- or amino acidcontaining nutritional supplement 3 months before start of or during the study, (c) consumption of more than $22 \mu \mathrm{g} /$ day vitamin $\mathrm{D}$ from vitamin supplement use, (d) consumption of 11.25-22 $\mu \mathrm{g}$ vitamin D daily from vitamin supplement use in combination with a serum calcidiol concentration $\geq 50 \mathrm{nmol} / \mathrm{L}$, (e) consumption of more than $500 \mathrm{mg}$ calcium daily from mineral supplement use.

\section{Study design}

The 13-week double-blinded RCT (known as the PROVIDE study) involved consumption of 2 servings of a vitamin D, calcium and leucine-enriched, whey protein medical nutrition drink (WP-MND) in the test group or 2 servings of an iso-caloric drink with only carbohydrates, fat and some trace elements in the control group [19]. This RCT was extended with a 13-week open-label extension (OLE) study period. Participants in the RCT who volunteered to participate in the OLE part of the study, were randomized to receive either 
1 or 2 servings of the WP-MND (FortiFit, Nutricia N.V., the Netherlands). One serving of WP-MND contained $21 \mathrm{~g}$ total protein, including $20 \mathrm{~g}$ whey protein and $3 \mathrm{~g}$ total leucine, $9 \mathrm{~g}$ carbohydrates, $3 \mathrm{~g}$ fat, $800 \mathrm{IU}(20 \mu \mathrm{g})$ vitamin $\mathrm{D}_{3}$, $500 \mathrm{mg}$ calcium, and a mixture of vitamins, minerals and fibers (for detailed composition see online supplementary material-Supplemental Table 1 of Bauer et al. [19]). The one-serving group took the WP-MND before breakfast. In the two-serving group, the regimen was the same as in the intervention group of the RCT, i.e. before breakfast and lunch [19].

\section{Outcome measures}

Parameters were assessed prior to the RCT (baseline RCT), at the end of the RCT, which was also the start of the OLE part of the study (week 13, Baseline OLE), and after the OLE study period (week 26). For determination of blood parameters, approximately $25.5 \mathrm{~mL}$ of venous blood was obtained at each visit. Blood samples in which creatinine $(\mu \mathrm{mol} / \mathrm{L})$, calcidiol $(\mathrm{nmol} / \mathrm{L})$, parathyroid hormone $(\mathrm{PTH}$, $\mathrm{pmol} / \mathrm{L})$, calcium $(\mathrm{mmol} / \mathrm{L})$ and albumin $(\mathrm{g} / \mathrm{L})$ were determined, were left at room temperature for $30 \mathrm{~min}$ and then centrifuged. Aliquots of serum were stored at -20 or $-80^{\circ} \mathrm{C}$ until analysis. These serum samples were analyzed at the Reinier de Graaf Groep medical laboratory, Delft, the Netherlands. Blood samples obtained for determination of the other parameters were processed and determined at the local laboratories on site, according to local procedures.

\section{Kidney function}

Kidney function was defined by the estimated glomerular filtration rate (eGFR, $\mathrm{mL} / \mathrm{min} / 1.73 \mathrm{~m}^{2}$ ) that was calculated with serum creatinine (Creat, $\mu \mathrm{mol} / \mathrm{L}$ ), using the Chronic Kidney Disease Epidemiology (CKD-EPI) Equation as described by Levey et al. [23]. Briefly, the CKD-EPI equation includes $\log$ [Creat] (modeled as a 2-slope linear spline with sex-specific $0.7 \mathrm{mg} / \mathrm{dL}$ in women and a $0.9 \mathrm{mg} / \mathrm{dL}$ in men), and gender, race, and age on a natural scale.

\section{Vitamin D and calcium metabolism}

Analytical testing for total serum calcidiol was performed using chemiluminescense micro-particulate immunoassay (Abbott Laboratories, Wiesbaden, Germany). To determine the effects of changes in the serum calcidiol on vitamin D metabolism, serum PTH and calcium were determined as well. Serum intact PTH concentrations were measured in serum using an ELISA [Intact parathyroid hormone, MD Biosciences Inc., St. Paul, MN 55108], with an intra-assay $\mathrm{CV}$ of $3.4 \%$. For albumin-corrected calcium, total serum calcium and albumin were measured by an automated system
[Instrumentation Laboratories UK Ltd, Cheshire, UK]. The intra-assay $\mathrm{CV}$ for serum calcium and albumin was $1.7 \%$ and $1.8 \%$, respectively. Serum calcium $(\mathrm{Ca})$ normally ranges between 2.15 and $2.55 \mathrm{mmol} / \mathrm{L}$ [24, 25]; therefore, hypercalcemia was defined as [Ca] $>2.55 \mathrm{mmol} / \mathrm{L}$ [25]. Serum calcium was adjusted for albumin according to the equation described by James et al. [26]:

Adjusted $[\mathrm{Ca}]=[$ total $\mathrm{Ca}]+0.02 *(40-[$ albumin $])$

In participants with calcidiol levels $\geq 100 \mathrm{nmol} / \mathrm{L}$ at baseline or during the study, serum calcium levels and adverse effects were closely evaluated.

\section{General safety and gastrointestinal tolerability}

Liver function was assessed at the local laboratories by determination of ALanine AminoTransferase (ALAT, U/L), ASparate AminoTransferase (ASAT, U/L), alkaline phosphatase (U/L), and gamma-Glutamyl Transpeptidase ( $\mathrm{y}-\mathrm{GT}$, $\mathrm{U} / \mathrm{L})$. Number and type of adverse events were registered. An adverse event was defined as any untoward medical occurrence in a clinical trial participant who was administered a study product, not necessarily implying a causal relationship with the intervention. The occurrence of adverse events was also checked between visits with intermittent phone calls. Gastrointestinal (GI) tolerability was assessed using a GI questionnaire at baseline, after 13 weeks and after 26 weeks of intervention. This questionnaire covered a range of GI symptoms: nausea, belching, feeling of fullness, vomiting, abdominal distension, flatulence, diarrhoea, constipation, dry mouth and thirst with a four-point scale (absent/mild /moderate/severe).

\section{Statistical analysis}

All the analysis of the main RCT paper [19] were done on the intention to treat (ITT) data set, while the safety and tolerability evaluation of the current paper was performed on the AST data set ( $n=379$ subjects), which excludes one subject in the control group who was randomized but did not start the intervention.

Normally distributed data were described as mean (SD or range) and analysed using the two-sample and paired $t$ test for between and within-group differences, respectively. Not normally distributed data were described as median (IQR or range) and analysed using the Mann-Whitney test for between-group differences and the Wilcoxon Signed-Rank test for within-group changes. A $p$ value $<0.05$ indicates a significant difference between groups. All statistical analyses were performed using SAS software (version 9.4; SAS, Inc, Cary, NC). 


\section{Results}

\section{Participants flow (Fig. 1)}

At the end of the 13-week RCT, 233 participants in the PROVIDE study agreed to participate in the OLE sequel of the study (test (T): $n=103$; control (C): $n=130) .133$ subjects were randomized into the 1-serving groups (CT1 and TT1) and 100 subjects were randomized into the 2-serving groups (CT2 and TT2). At the end of the OLE study, 214 participants completed the study (former $\mathrm{T}$ group receiving 1 serving of WP-MND during OLE (TT1): $n=57$, former T group receiving 2 serving of WP-MND during OLE (TT2): $n=39$, former $\mathrm{C}$ group receiving 1 serving of WP-MND during OLE (CT1): $n=72$, former $\mathrm{C}$ group receiving 2 serving of WP-MND during OLE (CT2): $n=46$ ), and 19 participants exited the study before week 26 .

\section{Characteristics of the study population}

Baseline characteristics of the RCT population are shown in the paper by Bauer et al. [19] and in Table 1 together with week 13 baseline characteristics of the 4 different OLE groups. Characteristics were not different between groups, neither at baseline for the RCT nor at baseline for the OLE study period, apart from a difference in total protein intake, serum calcidiol and PTH at the start of the OLE study period due to prior intervention in the RCT, which excludes potential selection bias in the OLE extension.

\section{Protein intake and kidney function}

During the RCT, supplementation with WP-MND led to a significant increase in median total protein intake from 1.0 (IQR: $0.9,1.2) \mathrm{g} / \mathrm{kg} \mathrm{BW} /$ day to 1.5 (IQR: $1.3,1.7$ ) g/kg $\mathrm{BW} /$ day in the test group $(p<0.001)$, with no change in the control group (T vs. C: $p<0.001$ ). Median protein intake ( $\mathrm{g} / \mathrm{kg} \mathrm{BW} /$ day) increased in the former RCT control groups during the OLE study period from 0.9 (IQR: $0.8,1.1$ ) to 1.3 (IQR: $1.1,1.5)$ in the CT1 $(p<0.001)$ and to 1.4 (IQR: 1.3 , $1.7) \mathrm{g} / \mathrm{kg} \mathrm{BW} /$ day in the CT2 group $(p<0.001)$. In the TT1 group that consumed one serving of WP-MND during the OLE study period after consumption of 2 servings during the RCT, median protein intake decreased from 1.5 (IQR: $1.3,1.7)$ to 1.2 (IQR: $1.1,1.4) \mathrm{g} / \mathrm{kg} \mathrm{BW} /$ day $(p<0.001)$ versus no change in the TT2 group (TT1 vs. TT2: $p<0.001$ ).
Fig. 1 Participants flow. WP$\mathrm{MND}$, a vitamin D and leucineenriched whey protein medical nutrition drink; T, test group during RCT; C, Control group during RCT; OLE, open-label extension; TT1, former RCT Test group receiving 1 serving of WP-MND during OLE; TT2, former RCT Test group receiving 2 servings of WPMND during OLE; CT1, former RCT Control group receiving 1 serving of WP-MND during OLE; CT2, former RCT Control group receiving 2 servings of WP-MND during OLE

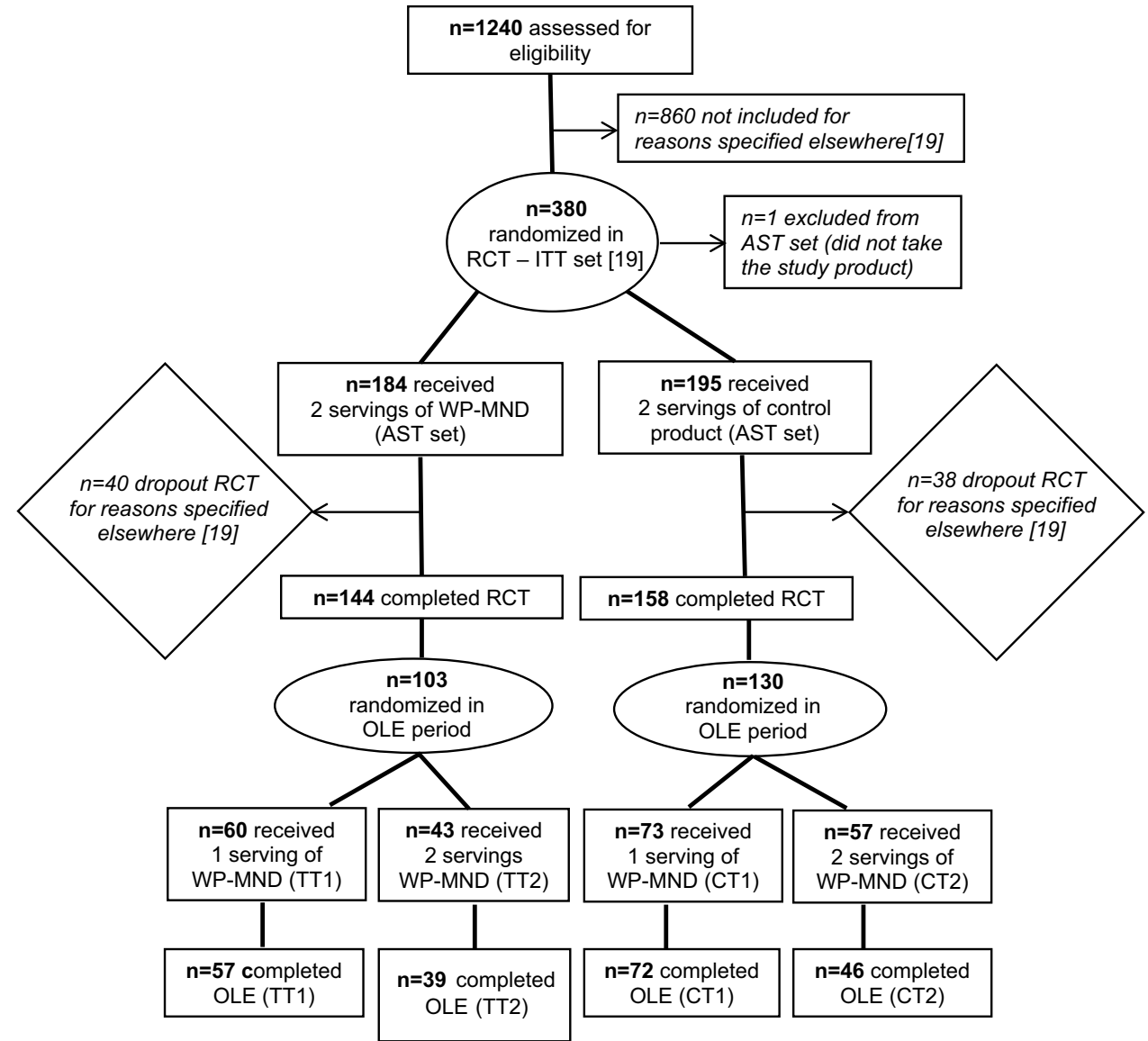


Table 1 Baseline (week 0) characteristics of RCT participants ( $n=279$, AST data set) and baseline (week 13) characteristics of participants in open-label extension of the study (OLE) $(n=233$, AST data set)

\begin{tabular}{|c|c|c|c|c|c|c|c|c|c|}
\hline & \multirow[t]{3}{*}{ Statistic } & \multirow{3}{*}{$\begin{array}{l}\text { Total RCT } \\
(n=379)\end{array}$} & \multicolumn{3}{|c|}{ Week 0 (baseline RCT) } & \multicolumn{4}{|c|}{ Week 13 (baseline OLE) } \\
\hline & & & \multirow{2}{*}{$\begin{array}{l}\text { Control } \\
(\mathrm{n}=195)\end{array}$} & \multirow[t]{2}{*}{ Test $(n=184)$} & \multirow{2}{*}{$\begin{array}{l}\text { Total OLE } \\
(\mathrm{n}=233)\end{array}$} & \multicolumn{2}{|c|}{ RCT control $(n=130)$} & \multicolumn{2}{|c|}{ RCT Test $(n=103)$} \\
\hline & & & & & & $\mathrm{CT} 1(\mathrm{n}=73)$ & $\mathrm{CT} 2(\mathrm{n}=57)$ & TT1 $(n=60)$ & TT2 $(n=43)$ \\
\hline Age (years) & $\begin{array}{l}\text { Mean } \\
\text { (SD) }\end{array}$ & $77.7(6.9)$ & $78.1(7.0)$ & $77.3(6.7)$ & $77.4(6.7)$ & $77.8(6.7)$ & $78.5(6.9)$ & $75.6(6.1)$ & $77.4(7.2)$ \\
\hline Sex (male) & $n(\%)$ & $131(34.6)$ & $67(34.4)$ & $64(34.8)$ & $90(38.6)$ & $27(37.0)$ & $25(43.9)$ & $25(41.7)$ & $13(30.2)$ \\
\hline $\begin{array}{l}\text { Living indepen- } \\
\text { dently }\end{array}$ & $n(\%)$ & $328(86.5)$ & $166(85.1)$ & $162(88.0)$ & 209 (89.7) & $65(89.0)$ & $47(82.5)$ & $58(96.7)$ & $39(90.7)$ \\
\hline MNA-SF, score & $\begin{array}{l}\text { Mean } \\
\text { (SD) }\end{array}$ & $13.1(1.3)$ & $13.1(1.5)$ & $13.2(1.2)$ & $13.2(1.2)$ & $13.2(1.2)$ & $13.1(1.4)$ & $13.4(1.0)$ & $13.3(1.1)$ \\
\hline Weight $(\mathrm{kg})$ & $\begin{array}{l}\text { Mean } \\
\quad(\mathrm{SD})\end{array}$ & $69.8(11.2)$ & $69.5(10.9)$ & $70.2(11.6)$ & $72.1(10.7)$ & $71.6(9.2)$ & $70.8(11.9)$ & $73.5(9.5)$ & $73.0(12.9)$ \\
\hline BMI $\left(\mathrm{kg} / \mathrm{m}^{2}\right)$ & $\begin{array}{l}\text { Mean } \\
\text { (SD) }\end{array}$ & $26.1(2.7)$ & $26.2(2.8)$ & $26.0(2.5)$ & $26.6(2.7)$ & $26.9(2.6)$ & $26.3(3.0)$ & $26.7(2.6)$ & $26.5(2.7)$ \\
\hline $\begin{array}{l}\text { Total protein } \\
\text { intake }(\mathrm{g} / \mathrm{kg} \\
\text { BW/day) }\end{array}$ & $\begin{array}{r}\text { Median } \\
(\mathrm{IQR})\end{array}$ & $1.0(0.8,1.2)$ & $1.0(0.8,1.2)$ & $1.0(0.9,1.2)$ & $1.1(0.9,1.5)$ & $0.9(0.8,1.1)$ & $0.9(0.8,1.0)$ & $1.5(1.3,1.7)$ & $1.5(1.3,1.7)$ \\
\hline $\begin{array}{l}\text { Total energy } \\
\text { intake (kcal/ } \\
\text { day) }\end{array}$ & $\begin{array}{r}\text { Median } \\
(\mathrm{IQR})\end{array}$ & $\begin{array}{l}1653 \\
\quad(1411,1964)\end{array}$ & $\begin{array}{l}1612 \\
\quad(1404,1919)\end{array}$ & $\begin{array}{l}1698 \\
\quad(1423,2028)\end{array}$ & $\begin{array}{l}1880 \\
\quad(1606,2208)\end{array}$ & $\begin{array}{l}1907 \\
\quad(1587,2163)\end{array}$ & $\begin{array}{l}1815 \\
\quad(1603,2011)\end{array}$ & $\begin{array}{l}1964 \\
\quad(1601,2275)\end{array}$ & $\begin{array}{l}1856 \\
(1638,2372)\end{array}$ \\
\hline $\begin{array}{l}\text { Dietary vitamin } \\
\text { D intake }(\mu \mathrm{g} / \\
\text { day) }\end{array}$ & $\begin{array}{r}\text { Median } \\
(\mathrm{IQR})\end{array}$ & $2.0(1.0,4.0)$ & $1.9(0.9,3.7)$ & $2.0(1.1,4.1)$ & $2.1(1.0,4.3)$ & $2.6(1.1,6.5)$ & $1.9(0.9,4.1)$ & $2.2(1.0,3.8)$ & $2.0(1.0,4.8)$ \\
\hline $\begin{array}{l}\text { Serum calcidiol } \\
(\mathrm{nmol} / \mathrm{L})\end{array}$ & $\begin{array}{r}\text { Median } \\
(\mathrm{IQR})\end{array}$ & $48.0(34.0,66.0)$ & $49.0(34.0,65.0)$ & $48.0(33.0,66.0)$ & $64.0(39.0,80.0)$ & $43.0(30.0,58.5)$ & $41.0(28.0,57.0)$ & $81.0(69.0,96.0)$ & $77.0(68.0,88.0)$ \\
\hline PTH (pmol/L) & $\begin{array}{l}\text { Median } \\
(\mathrm{IQR})\end{array}$ & $5.7(4.2,7.7)$ & $5.7(4.2,7.5)$ & $5.9(4.2,8.1)$ & $5.3(3.8,7.4)$ & $5.8(4.5,7.7)$ & $6.1(5.2,8.2)$ & $4.6(3.6,6.9)$ & $4.3(3.4,5.7)$ \\
\hline $\begin{array}{l}\text { Calcium } \\
\text { corrected } \\
\text { for albumin } \\
(\mathrm{mmol} / \mathrm{L})\end{array}$ & $\begin{array}{l}\text { Mean } \\
\text { (SD) }\end{array}$ & $2.3(0.14)$ & $2.31(0.15)$ & $2.29(0.12)$ & $2.31(0.14)$ & $2.30(0.15)$ & $2.30(0.17)$ & $2.33(0.11)$ & $2.33(0.12)$ \\
\hline $\begin{array}{l}\text { Creatinine } \\
(\mu \mathrm{mol} / \mathrm{L})\end{array}$ & $\begin{array}{l}\text { Mean } \\
\quad(\mathrm{SD})\end{array}$ & $76.1(21.7)$ & 76.7 (21.7) & $75.5(21.8)$ & $76.3(20.3)$ & $76.2(18.7)$ & $79.7(21.0)$ & $74.4(21.3)$ & $74.4(20.9)$ \\
\hline $\begin{array}{l}\text { eGFR }(\mathrm{mL} / \\
\left.\mathrm{min} / 1.73 \mathrm{~m}^{2}\right)\end{array}$ & $\begin{array}{l}\text { Mean } \\
\quad(\mathrm{SD})\end{array}$ & $73.5(15.9)$ & 73.0. (16.4) & $74.1(15.4)$ & $73.9(15.6)$ & $73.0(15.4)$ & $71.5(15.8)$ & $77.1(14.4)$ & $74.3(17.2)$ \\
\hline ALAT (U/L) & $\begin{array}{l}\text { Mean } \\
\quad(\mathrm{SD})\end{array}$ & $20.2(8.1)$ & $20.1(8.5)$ & $20.2(7.6)$ & $23.1(14.6)$ & $23.4(17.7)$ & $20.9(9.0)$ & $25.7(18.0)$ & $22.3(8.3)$ \\
\hline ASAT (U/L) & $\begin{array}{l}\text { Mean } \\
\quad(S D)\end{array}$ & $23.6(6.4)$ & $23.4(6.7)$ & $23.9(6.1)$ & $25.1(14.5)$ & $26.7(23.7)$ & $24.2(6.8)$ & $25.0(8.0)$ & $23.9(6.0)$ \\
\hline ALP (U/L) & $\begin{array}{l}\text { Mean } \\
\quad(S D)\end{array}$ & $77.4(25.2)$ & $78.3(27.6)$ & $76.3(22.3)$ & $78.2(28.5)$ & $81.5(40.0)$ & $79.3(22.5)$ & $77.3(23.0)$ & $72.8(18.1)$ \\
\hline y-GT (U/L) & $\begin{array}{l}\text { Mean } \\
\text { (SD) }\end{array}$ & $29.3(30.9)$ & $29.7(30)$ & $29.0(31.9)$ & $30.7(32.5)$ & $31.8(28.2)$ & $26.5(20.5)$ & $36.1(50.2)$ & $26.9(16.9)$ \\
\hline
\end{tabular}

CT1, former RCT Control group receiving 1 serving of WP-MND during OLE; CT2, former RCT Control group receiving 2 servings of WPMND during OLE; TT1, former RCT Test group receiving 1 serving of WP-MND during OLE; TT2, former RCT Test group receiving 2 servings of WP-MND during OLE

The study population had a median eGFR of 77 (IQR: 63, 87) $\mathrm{mL} / \mathrm{min} / 1.73 \mathrm{~m}^{2}$ at baseline, prior to the RCT. 13-week supplementation with 2 servings of the WP-MND during the RCT led to a small increase in eGFR in the test group (median change 1.0 (IQR: - 2.8, 4.2) $\mathrm{mL} / \mathrm{min} / 1.73 \mathrm{~m}^{2}$; $p=0.013$ ) versus no significant change in the control group (median change $-1.1(\mathrm{IQR}:-4.9,2.8) \mathrm{mL} / \mathrm{min} / 1.73 \mathrm{~m}^{2}$; $p=0.067$ )(T vs. C: $p=0.002$ ) (Fig. 2a). No change in eGFR was observed during the OLE part of the study (Fig. 2b). Some of the participants (T: $n=36$ and C: $n=39$ ) had an eGFR between 30 and $60 \mathrm{~mL} / \mathrm{min} / 1.73 \mathrm{~m}^{2}$ at baseline, before the start of the RCT, which is defined as moderate chronic kidney disease (CKD). In this vulnerable subgroup, the same trend in eGFR was observed as in the total study population. During the RCT, eGFR increased in participants with moderate CKD at baseline in the test group from median 52 (IQR: $48.1,56.2$ ) to 56.2 (IQR: $46.5,63.8 ; p=0.007) \mathrm{mL} /$ $\min / 1.73 \mathrm{~m}^{2}$ vs. no change in the control group ( $\mathrm{T}$ vs. $\mathrm{C}$ : NS). No further change was observed during OLE within or between the moderate CKD subgroups. 


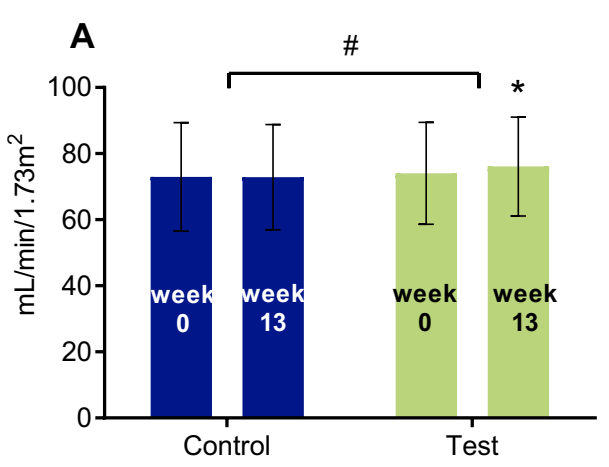

Fig. 2 Estimated glomerular filtration rate (eGFR) in the RCT (a), and OLE population (b). Results are expressed as median (IQR). This figure shows the eGFR in the RCT population at baseline (week 0) and after intervention (week 13) with 2 servings of a vitamin D, calcium and leucine enriched whey protein medical nutrition drink (WPMND) (Test) or Control product (Control) (a), and in the open-label extension (OLE) population at baseline (week 13) and after inter-

\section{Leucine intake}

Based on the reported protein intake data and the estimation that dietary protein contains on average $7.8 \%$ leucine [27], the total daily leucine intake from the diet and the WP-MND was calculated. The median baseline intake of leucine from the diet at the start of the RCT was estimated to be around $0.078 \mathrm{~g} / \mathrm{kg} \mathrm{BW} /$ day ( $1.0 \mathrm{~g}$ protein $/ \mathrm{kg} \mathrm{BW} /$ day). At week 13, leucine intake from the diet was estimated to be around $0.070 \mathrm{~g} / \mathrm{kg} \mathrm{BW} /$ day $(0.9 \mathrm{~g}$ protein $/ \mathrm{kg} \mathrm{BW} /$ day $)$ in $50 \%$ (median) and $0.086 \mathrm{~g} / \mathrm{kg} \mathrm{BW} /$ day $(1.1 \mathrm{~g}$ protein $/ \mathrm{kg}$ BW/day) in $75 \%$ (upper IQR) of the test group. The WPMND supplement contributed to an additional $6 \mathrm{~g}$ leucine per day, representing $0.086 \mathrm{~g} / \mathrm{kg} \mathrm{BW} /$ day based on a median

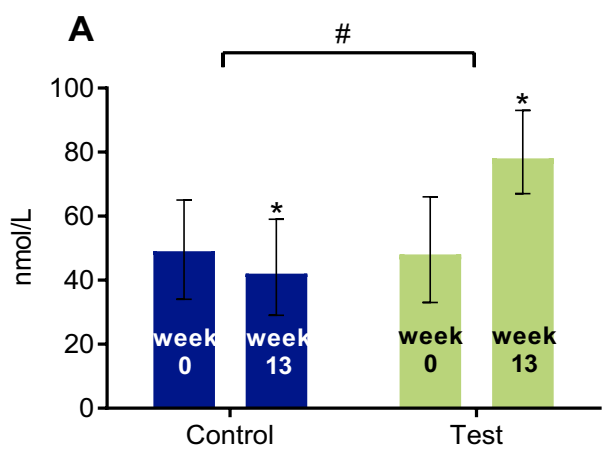

Fig. 3 Serum levels of 25-hydroxy-vitamin D (calcidiol) in the RCT (a), and OLE population (b). Results are expressed as median (IQR). This figure shows the serum concentrations of calcidiol in the RCT population at baseline (week 0) and after intervention (week 13) with 2 servings of a vitamin $\mathrm{D}$, calcium and leucine enriched whey protein medical nutrition drink (WP-MND) (Test) or control product (Control) (a), and in the OLE population at baseline (week 13) and after intervention (week 26) with one or two servings of WP-MND (b).

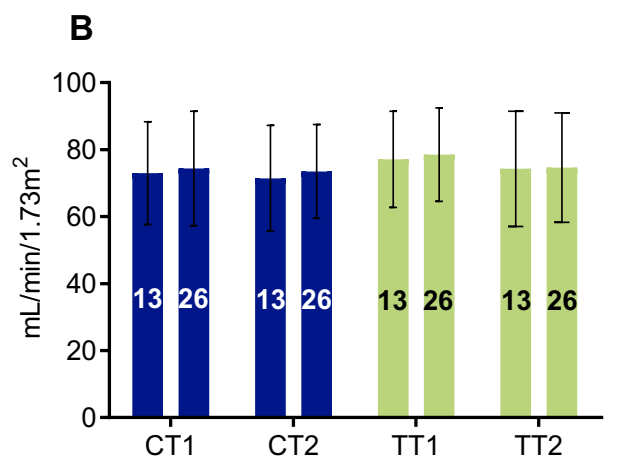

vention (week 26) with one or two servings of WP-MND) (b). CT1, former RCT Control group receiving 1 serving of WP-MND during OLE; CT2, former RCT Control group receiving 2 servings of WPMND during OLE; TT1, former RCT Test group receiving 1 serving of WP-MND during OLE; TT2, former RCT Test group receiving 2 servings of WP-MND during OLE. "Significant difference in change between Test and Control groups. * Significant change within group

bodyweight of $70 \mathrm{~kg}$. In total, leucine intake in the WPMND group was $0.171 \mathrm{~g} / \mathrm{kg}$ BW/day in $75 \%$ of subjects, which is well below the TUL for leucine of $0.5 \mathrm{~g} / \mathrm{kg} \mathrm{BW} /$ day [28-30].

\section{Vitamin D and calcium metabolism}

After 13 weeks of intervention with 2 servings of the WPMND in the test group, a significant increase in median serum calcidiol $(p<0.001)$ was observed versus a significant decrease $(p<0.001)$ in the control population (T vs. C: $p<0.001$ ) (Fig. 3a). No further increase was observed in either of the former test groups (TT1 and TT2) during the OLE study period (13 vs. 26 weeks) (Fig. 3b). On the

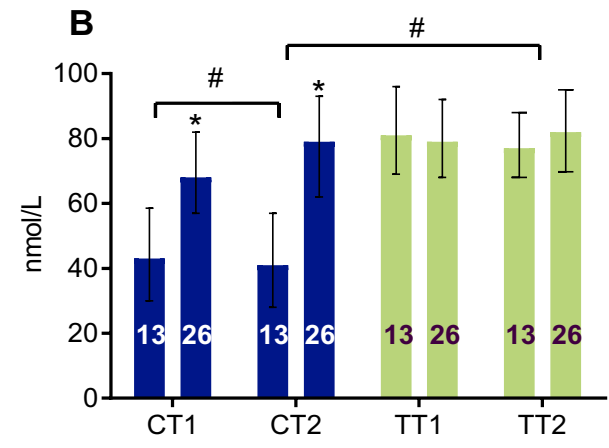

CT1, former RCT Control group receiving 1 serving of WP-MND during OLE; CT2, former RCT Control group receiving 2 servings of WP-MND during OLE; TT1, former RCT Test group receiving 1 serving of WP-MND during OLE; TT2, former RCT Test group receiving 2 servings of WP-MND during OLE. "Significant difference in change between Test and Control groups. * Significant change within group 
other hand, a significant increase in calcidiol levels was observed in the participants who switched from the control product during the RCT to the test product in the OLE study period (both CT1, CT2: $p<0.001$ ) and most in the group that received 2 servings of the WP-MND (CT1 vs. CT2: $p<0.001$ ).

Fourteen participants had a serum calcidiol concentration $\geq 100 \mathrm{nmol} / \mathrm{L}$ at baseline, prior to the RCT (T: $n=6$; C: $n=8)$. In 20 participants with normal calcidiol levels at baseline, calcidiol increased above $100 \mathrm{nmol} / \mathrm{L}$ during the RCT (T: $n=18, \mathrm{C}: n=2$ ). During the OLE study period, the number of participants with serum calcidiol levels $\geq 100 \mathrm{nmol} / \mathrm{L}$ decreased in the former test groups (T: $\mathrm{n}=20 \rightarrow 16)$ and increased in the former control groups (C: $n=6 \rightarrow 9$ ). In 13 OLE participants (T: $n=10 ; \mathrm{C}: n=3$ ) with calcidiol levels $\geq 100$ at week 13 , serum calcidiol increased further at week 26 (range of increase: $2-38 \mathrm{nmol} / \mathrm{L}$ ), independent of the number of servings.

During the RCT, serum levels of PTH decreased in the test group $(p<0.001)$ and increased in the control group ( $p=0.006$ ) (Fig. 4a). Serum levels of PTH did not change with continued supplementation of a WP-MND but decreased significantly in participants who switched from control to test product during the OLE study period $(p<0.001)$ (Fig. 4b).

During the RCT, the albumin-adjusted serum calcium concentration increased in the test group from 2.29 to $2.33 \mathrm{mmol} / \mathrm{L}(p<0.001)$ versus no change in the control group (mean: $2.31 \mathrm{mmol} / \mathrm{L}$; T vs. C: $p<0.001$ ) (Fig. $5 \mathrm{a}$ ). During the OLE study period, calcium levels increased in the former control population (CT1: $p=0.017$; CT2: $p=0.003$ ) whereas no further increase was observed in the former test population (Fig. 5b). Although albumin-corrected calcium levels $>2.55 \mathrm{mmol} / \mathrm{L}$ were observed, the proportion of participants with hypercalcaemia was not different between groups (Table 2). At baseline, 12 subjects already manifested albumin-corrected calcium levels above $2.55 \mathrm{mmol} / \mathrm{L}$ (T: $n=3 ; \mathrm{C}: n=9$ ). During the RCT, a similar number of subjects in the test and control group developed hypercalcaemia (T: $n=3$; C: $n=3$ ), while 8 (T: $n=2$; C: $n=6$ ) of the 14 subjects with hypercalcemia at week 13 already had elevated levels at baseline. This suggests no direct association between the development of hypercalcemia and supplementation of WP-MND but may point to a surprisingly higher prevalence of hypercalcemia in this sarcopenic older population. In OLE extension with 2 servings per day (CT2), 2 subjects maintained the elevated calcium levels and 3 new subjects were found with calcium levels above $2.55 \mathrm{mmol} / \mathrm{L}$. In the OLE group taking 1 serving a day (CT1), 3 subjects maintained higher calcium levels, while 2 subjects with the elevation of calcium above $2.55 \mathrm{mmol} / \mathrm{L}$ were found. The presence of hypercalcemia at baseline or development of hypercalcemia during the study in any of the groups showed no connection to evolvement over time of PTH, calcidiol, creatinine, and eGFR.

At the start of RCT, none of the 14 participants with calcidiol levels above $100 \mathrm{nmol} / \mathrm{L}$ had albumin-corrected calcium levels above $2.55 \mathrm{mmol} / \mathrm{L}$. At week 13 (end RCT and start OLE), 3 out of 26 participants with calcidiol above $100 \mathrm{nmol} / \mathrm{L}$ (from the former test group) had albumin-corrected calcium levels above $2.55 \mathrm{mmol} / \mathrm{L}$. At week 26 (end OLE), 3 out of 25 participants had both levels elevated (1 from the TT1, 1 from the TT2 and 1 from the CT2 group) of which for one of them (from the TT2 group) this was already the case at baseline OLE.

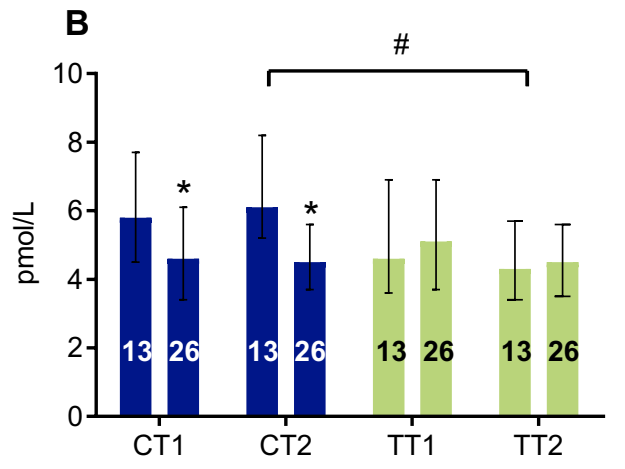

vention (week 26) with one or two servings of WP-MND (b). CT1, former RCT Control group receiving 1 serving of WP-MND during OLE; CT2, former RCT Control group receiving 2 servings of WPMND during OLE; TT1, former RCT Test group receiving 1 serving of WP-MND during OLE; TT2, former RCT Test group receiving 2 servings of WP-MND during OLE. "Significant difference in change between Test and Control groups. * Significant change within group
Fig. 4 Serum levels of parathyroid hormone (PTH) in the RCT (a), and OLE population (b). Results are expressed as median (IQR). This figure shows the serum concentrations of PTH in the RCT population at baseline (week 0) and after intervention (week 13) with 2 servings of a vitamin D, calcium and leucine enriched whey protein medical nutrition drink (WP-MND) (Test) or Control product (Control) (a), and in the OLE population at baseline (week 13) and after inter- 


\section{General safety, vital signs}

Parameters of liver function did not increase during the RCT or OLE study period and values were within the range of reference values (Table 1).

At baseline, heart rate was significantly higher in the test group compared to the control group $(p=0.011)$, but no significant changes in heart rate, systolic and diastolic blood pressure were observed between the two groups after 13 weeks of intervention (Table 3 in Appendix). At OLE baseline (week 13), heart rate in TT1 was significantly lower compared to the TT2 group ( $p=0.018)$, but no other significant differences were found between the groups at week 26 . Similarly, no significant differences were found in systolic or diastolic blood pressure between the different groups (CT1 vs. CT2; TT1 vs. TT2; CT2 vs. TT2) during the OLE extension (Table 4 in Appendix).

\section{Adverse events}

During the RCT, a total of 557 adverse events were reported among 240 subjects. From those, 193 were assessed as being related to the study products, without a significant difference between the test group (46 subjects; $25.0 \%$ ) and the control

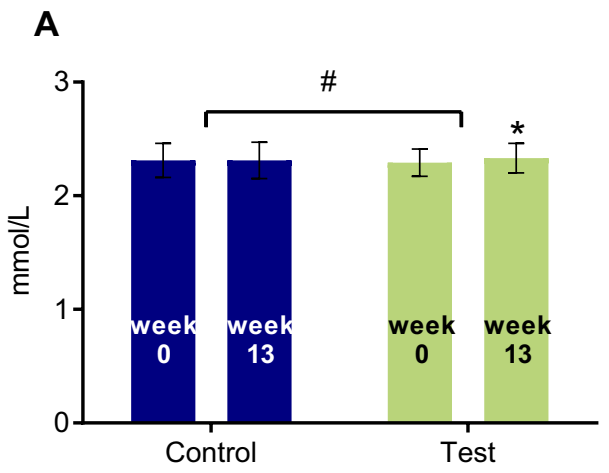

Fig. 5 Albumin-adjusted serum levels of calcium in the RCT (a), and OLE population (b). Results are expressed as mean (SD). This figure shows the albumin-adjusted serum concentrations of calcium in the RCT population at baseline (week 0) and after intervention (week 13) with 2 servings of a vitamin $\mathrm{D}$, calcium and leucine enriched whey protein medical nutrition drink (WP-MND) (Test) or Control product (Control) (a), and in the OLE population at baseline (week 13) and after intervention (week 26) with one or two servings of WP-MND group (54 subjects; $27.7 \%)(p=0.562)$. In the OLE study period, a total of 216 adverse events were reported among 112 subjects. From those, 57 were assessed as being related to the study product. The number of subjects reporting one or more related adverse events was significantly higher in the TT2 group ( 9 subjects; 20.9\%) compared to the TT1 group (only 3 subjects; $5 \%)(p=0.026)$. Since other betweengroups comparisons did not show a significant difference (TT2 vs. CT2 and CT2 vs. CT1), there was no apparent doserelationship and the data did not point to any concern. The most commonly reported related adverse events were gastrointestinal (such as abdominal pain and nausea) or metabolic and nutritional disorders (such as hyperglycaemia). No treatment-related serious adverse events occurred during the RCT and OLE study periods. Moreover, no related adverse (serious or non-serious) events, including nephrolithiasis (kidney stones), were observed in participants with serum calcidiol levels $\geq 100 \mathrm{nmol} / \mathrm{L}$ or with albumin-adjusted calcium levels $>2.55 \mathrm{mmol} / \mathrm{L}$, at any of the time points.

\section{Gastrointestinal tolerability}

The incidence and the severity of the self-reported GI symptoms (nausea, belching, feeling of fullness, vomiting,

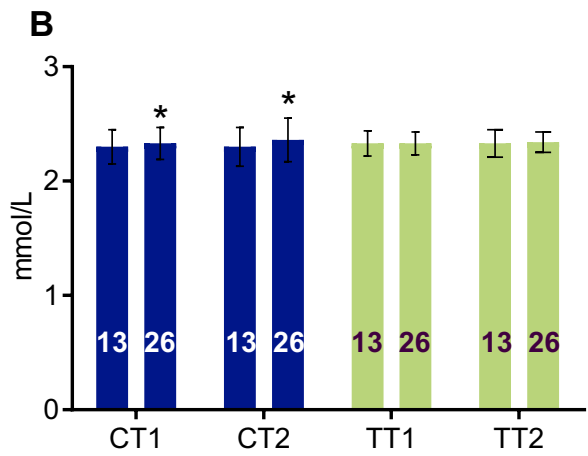

(b). CT1, former RCT Control group receiving 1 serving of WPMND during OLE; CT2, former RCT Control group receiving 2 servings of WP-MND during OLE; TT1, former RCT Test group receiving 1 serving of WP-MND during OLE; TT2, former RCT Test group receiving 2 servings of WP-MND during OLE. "Significant difference in change between Test and Control groups. * Significant change within group
Table 2 Prevalence $(n$, $\%)$ of hypercalcaemia (albumin corrected calcium $>2.55 \mathrm{mmol} / \mathrm{L}$ ) during RCT and open-label extension of the study (OLE)

\begin{tabular}{|c|c|c|c|c|c|c|}
\hline & Control & Test & CT1 & $\mathrm{CT} 2$ & TT1 & TT2 \\
\hline Baseline RCT (week 0) & $9(4.8 \%)$ & $3(1.7 \%)$ & $3(4.3 \%)$ & $4(7.7 \%)$ & $2(3.4 \%)$ & $0(0.0 \%)$ \\
\hline End RCT/baseline OLE (week 13) & $9(5.8 \%)$ & $4(2.9 \%)$ & $4(5.6 \%)$ & $2(3.5 \%)$ & $1(1.7 \%)$ & $1(2.4 \%)$ \\
\hline End OLE (week 26) & $10(8.7 \%)$ & $1(1.1 \%)$ & $5(6.9 \%)$ & $5(11.6 \%)$ & $1(1.8 \%)$ & $0(0.0 \%)$ \\
\hline
\end{tabular}

CT1, former RCT Control group receiving 1 serving of WP-MND during OLE; CT2, former RCT Control group receiving 2 servings of WP-MND during OLE; TT1, former RCT Test group receiving 1 serving of WP-MND during OLE; TT2, former RCT Test group receiving 2 servings of WP-MND during OLE 
abdominal distension, flatulence, diarrhoea, constipation, dry mouth and thirst) did not differ between the control and the test group at baseline or the end of the RCT (Table 5 in Appendix). Moreover, no difference was observed between the two groups with regards to the changes at week 13 relative to the baseline for any of the GI symptoms. The OLE study also showed no difference in the incidence or severity of the GI symptoms between the groups (CT1 vs. CT2; TT1 vs. TT2; CT2 vs. TT2), except for diarrhoea which was significantly lower in CT2 compared to CT1 $(p=0.01)$ (Table 6 in Appendix).

\section{Discussion}

6-month intervention with up to 2 servings of this WP-MND in addition to a regular diet neither impaired kidney function nor caused vitamin D and/or calcium toxicity and is not related to impaired liver function and vital signs, increased gastro-intestinal intolerance or -adverse events.

\section{Protein intake and kidney function}

The consistent high protein intake in line with recommendations, especially in participants receiving 2 servings of WP-MND throughout the entire 26-week study period (during RCT and OLE), enabled evaluation of the effect of a prolonged high protein intake on kidney function.

Concerns regarding the adverse effect of a high protein diet on kidney function are related to glomerular hyperfiltration and hypertensive effects [31-33]. During the RCT, eGFR increased in the test vs. no change in the control group $(p=0.002)$. The same trend was observed in the subgroup of participants with moderate CKD at baseline. During OLE, no (further) change in eGFR was observed in any of the (sub)groups. The alteration of eGFR in response to a high protein diet is in line with observations by others and is thought to be an adaptive response to the protein feeding and not the development of CKD per se [31, 33, 34]. The observed plateau in eGFR after 13 weeks of treatment with 2 servings of WP-MND during the OLE period, supports this notion of adaptation. Moreover, the observed increase and subsequent plateau of eGFR after 13 weeks of treatment in older people with moderate CKD suggest that even those individuals still tolerate a high protein diet. However, caution is still warranted, and kidney function should be monitored on a regular basis in people on a high protein diet with moderate CKD, as recommended [7, 9, 12]. Furthermore, blood pressure did not change over time and was not different between groups, which supports the assumption that the observed increase of eGFR was not an indication of early kidney failure.

\section{Vitamin D and calcium metabolism}

Calcidiol levels increased with the intake of 2 servings of WP-MND, providing $40 \mu \mathrm{g}$ vitamin D, and reached a plateau at $\sim 80 \mathrm{nmol} / \mathrm{L}$ after 3 months of supplementation. Moreover, 1 serving of WP-MND providing $20 \mu \mathrm{g}$ vitamin D also increased calcidiol levels after 3 months, although to a lesser extent $(\sim 70 \mathrm{nmol} / \mathrm{L})$, hence suggesting a dose-response effect. When considering a baseline diet with a median vitamin D intake of 2.0 (IQR: 1.0, 4.0) $\mu \mathrm{g} /$ day at the beginning of the RCT and 2.1 (IQR: 1.0, 4.3) $\mu \mathrm{g} /$ day at the beginning of OLE (Table 1), the total intake of vitamin D did not exceed $50 \mu \mathrm{g} /$ day. This amount is well below the TUL for vitamin D intake at $100 \mu \mathrm{g}$ per day set by EFSA [35]. For adults, EFSA selected hypercalcemia as the indicator of vitamin D toxicity that may occur when plasma levels of calcidiol increase above $100 \mathrm{nmol} / \mathrm{L}$ [5, 15, 36-39]. In our study, some participants had calcidiol levels $\geq 100 \mathrm{nmol} / \mathrm{L}$ with or without hypercalcemia (albumin-corrected calcium levels $>2.55 \mathrm{mmol} / \mathrm{L}$ ) at baseline or during the study. However, no causal relation was observed between high serum calcidiol and calcium levels and no related adverse events were reported. An explanation for high plasma calcidiol levels may be an enhanced endogenous skin vitamin D production following exposure to sunlight $[40,41]$ or clandestine consumption of vitamin D containing food supplements.

Although no relationship was observed between hypercalcidiol and hypercalcemia, the overall increase in serum calcium was significant but marginal in the test group during the RCT, and in the control group during OLE. This increase was observed to plateau after 3 months of supplementation with 2 servings of WP-MND. The total group average serum calcium level at baseline was $2.30 \mathrm{mmol} / \mathrm{L}$ (not different between groups), which is within the reference range of 2.15-2.6 mmol/L [24]. Twelve participants had hypercalcemia at baseline of the RCT, which is a surprisingly higher prevalence than reported in other populations, such as in the community and hospital $(0.2-4 \%[42,43])$. This warrants confirmation of potentially unknown hypercalcemia cases among the sarcopenic population in future research. The prevalence of hypercalcemia did not change during the course of the RCT and the OLE study periods, with some participants maintaining hypercalcemia and others developing hypercalcemia, independent of the treatment group. The presence or development of hypercalcemia could not be linked to clinically relevant safety indicators or adverse events. As expected, serum parathyroid hormone (PTH) levels decreased with the intake of the WP-MND. Therefore, hyperparathyroidism was unlikely to be the cause of observed hypercalcemia. Another cause for hypercalcemia could be due to the calcium provided (1000 $\mathrm{mg}$ in 2 servings of WP-MND on top of the diet providing on average about $1000 \mathrm{~g} /$ day of calcium), leaving a margin of $500 \mathrm{mg}$ before 
exceeding the TUL as established by EFSA [44]. However, the Panel considers that no relationship has been established between long-term calcium intakes at $2.5 \mathrm{~g} / \mathrm{day}$ from diet and supplements and increased risk of nephrolithiasis.

\section{General safety and gastrointestinal tolerability}

There was no difference in the number and origin of the adverse events between test and (former) control groups. Most of the adverse events were gastrointestinal, but the incidence and severity of gastrointestinal symptoms did not differ between the treatment groups. No potentially treatmentrelated serious adverse events were observed. Moreover, no adverse (serious or non-serious) events were observed in participants with serum calcidiol levels $\geq 100 \mathrm{nmol} / \mathrm{L}$ or with albumin-adjusted calcium levels $>2.55 \mathrm{mmol} / \mathrm{L}$, at any of the time points. Finally, vital signs did not change throughout the study, and parameters of liver function were within the reference range and did not increase in any of the groups during the RCT or OLE study period.

\section{Strengths and limitations}

The main strength of this investigation is the evaluation of the safety of an effective medical nutrition drink in a study group of sarcopenic older adults $(n=380)$ [19]. Detailed information was collected about the impact of 1-2 servings of WP-MND on protein intake, kidney function, vitamin $\mathrm{D}$ and calcium metabolism. Furthermore, participants with moderate CKD, supra-normal levels of calcidiol or hypercalcemia were separately analyzed and scrutinized for adverse effects. Another strength is that we observed a plateau after 3-months of WP-MND supplementation for eGFR and plasma levels of calcidiol, calcium and PTH, suggesting that the study period was likely long enough to demonstrate that consumption of two servings of WP-MND is safe in the longer term. A study limitation may be that treatment groups were small during OLE, although observed effects point in the same direction as during the RCT. Another limitation may be that we did not determine plasma ammonia and insulin resistance over time, which are indicative of short-term leucine toxicity and potential negative effects of leucine supplementation in longer term [45]. Furthermore, eGFR should perhaps have been monitored over an even longer period to ensure that the observed increase in eGFR in the test population just represented an adaptation to the high protein intake.

In conclusion, a 6-month intake of a vitamin $\mathrm{D}$, calcium and leucine-enriched whey protein medical nutrition drink in addition to a regular diet does not impair kidney function or disturb vitamin $\mathrm{D}$ and calcium metabolism in sarcopenic older adults. Furthermore, WP-MND does not affect liver function and vital signs and is well tolerated by the gastrointestinal tract. In line with the protein recommendations, we do recommend monitoring of kidney function in consumers with moderate CKD [9]. For kidney protection in general, sufficient fluid intake is recommended for proper hydration [46].

Acknowledgements Open Access funding provided by Projekt DEAL. We thank all participants for their participation in RCT and the voluntary open-label extension study period dedicating their time and energy. We are grateful to the research staff members at each study site for their commitment to achieving the aims of this study. We are thankful to the PROVIDE study group* for their professional oversight and guidance. We are thankful to Gerdien Ligthart-Melis, $\mathrm{PhD}$ (GCLM-Nutriscience) for drafting this manuscript and Laure Verstraeten for creating the tables on GI tolerability and vital signs, as well as a quality check of all the data reported in the paper. *PROVIDE study group members: Jürgen M Bauer, Sjors Verlaan, Ivan Bautmans, Kirsten Brandt, Lorenzo M Donini, Marcello Maggio, Marion ET McMurdo, Tony Mets, Chris Seal, Sander LJ Wijers, Gian Paolo Ceda, Giuseppe De Vito, Gilbert Donders, Michael Drey, Carolyn Greig, Ulf Holmbäck, Marco Narici, Jamie McPhee, Eleonora Poggiogalle, Dermot Power, Aldo Scafoglieri, Ralf Schultz, Cornel Sieber, Tommy Cederholm.

Funding This study was financially supported and study products were provided by Danone Nutricia Research, Nutricia Advanced Medical Nutrition. The funding source was involved at all stages of the study.

\section{Compliance with ethical standards}

Conflict of interests Jürgen Bauer is a scientific advisor and has received research grants and speakers honorarium from Nutricia and Nestlé. Lucia Mikušová, Sander Wijers and Yvette Luiking are employed by Danone Nutricia Research, Sjors Verlaan was an employee in the past and Jossie Garthoff works for Danone Food Safety Center. Tommy Cederholm has given remunerated lectures and has received unconditional research grants from Nutricia and Nestlé. Kirsten Brandt received a research grant from Nutricia Research during the conduct of the study. Ivan Bautmans, Tony Mets, Lorenzo M Donini, Marcello Maggio and Cornel Sieber declare that they have no conflict of interest.

Statement of human and animal rights The study protocol was reviewed and approved by The Research Ethics Boards at each of the locations and was published and registered with the Dutch trials register with the identifier: NTR2329 (https://www.trialregister.nl/trialreg). Study procedures were performed in accordance with the Declaration of Helsinki ethical principles for medical research involving human subjects.

Informed consent All participants gave written informed consent prior to the RCT and volunteered to participate in the open-label extension of the study.

Open Access This article is licensed under a Creative Commons Attribution 4.0 International License, which permits use, sharing, adaptation, distribution and reproduction in any medium or format, as long as you give appropriate credit to the original author(s) and the source, provide a link to the Creative Commons licence, and indicate if changes were made. The images or other third party material in this article are included in the article's Creative Commons licence, unless indicated otherwise in a credit line to the material. If material is not included in the article's Creative Commons licence and your intended use is not permitted by statutory regulation or exceeds the permitted use, you will need to obtain permission directly from the copyright holder. To view a copy of this licence, visit http://creativecommons.org/licenses/by/4.0/. 


\section{Appendix}

See Tables 3, 4, 5, 6 .

Table 3 Measured vital signs at baseline of the RCT study (week 0) and at the end of the RCT study (week 13) in the control and the test group

\begin{tabular}{|c|c|c|c|c|c|}
\hline \multirow[t]{2}{*}{ Vital signs } & \multirow[t]{2}{*}{ Statistic } & \multicolumn{2}{|c|}{ Week 0 (baseline RCT) } & \multicolumn{2}{|c|}{ Week 13 (end RCT, baseline OLE) } \\
\hline & & Control $(n=195)$ & Test $(n=184)$ & Control $(n=196)$ & Test $(n=184)$ \\
\hline Heart rate (bpm) & Mean (SD) & $69.2(11.3)$ & $72.1(11.1)^{*}$ & $69.5(11.2)$ & $71.5(10.3)$ \\
\hline Systolic blood pressure (mmHg) & Mean (SD) & $141(20.8)$ & $137(18.2)$ & $138.8(20.4)$ & $134.8(15.8)$ \\
\hline Diastolic blood pressure $(\mathrm{mmHg})$ & Mean (SD) & $76(10.4)$ & $75.6(10.3)$ & $76.4(10.2)$ & $74.7(9.5)$ \\
\hline
\end{tabular}

CT1, former RCT Control group receiving 1 serving of WP-MND during OLE; CT2, former RCT Control group receiving 2 servings of WPMND during OLE; TT1, former RCT Test group receiving 1 serving of WP-MND during OLE; TT2, former RCT Test group receiving 2 servings of WP-MND during OLE

*Significant difference between control and test; $p$ value $=0.011(t$ test $)$

Table 4 Vital signs at baseline of the open-label extension (week 13) and at the end of the OLE study period (week 26)

\begin{tabular}{|c|c|c|c|c|c|c|c|c|c|}
\hline \multirow[t]{3}{*}{ Vital signs } & \multirow[t]{3}{*}{ Statistic } & \multicolumn{4}{|c|}{ Week 13 (baseline OLE) } & \multicolumn{4}{|l|}{ Week 26} \\
\hline & & \multicolumn{2}{|c|}{ RCT control $(n=130)$} & \multicolumn{2}{|c|}{ RCT tests $(n=103)$} & \multicolumn{2}{|c|}{ RCT control $(n=130)$} & \multicolumn{2}{|c|}{ RCT tests $(n=103)$} \\
\hline & & CT1 $(n=73)$ & CT2 $(n=57)$ & TT1 $(n=60)$ & TT2 $(n=43)$ & CT1 $(n=73)$ & $\mathrm{CT} 2(n=57)$ & TT1 $(n=60)$ & $\mathrm{TT} 2(n=43)$ \\
\hline $\begin{array}{l}\text { Heart rate } \\
(\text { (bpm) }\end{array}$ & Mean (SD) & $67.1(10.9)$ & $71(11.3)$ & $69.2(11.5)$ & $74.4(9.7)^{*}$ & $67.8(10.8)$ & $69.6(10.4)$ & $70.4(10.3)$ & $73.4(9.6)$ \\
\hline $\begin{array}{l}\text { Systolic blood } \\
\text { pressure } \\
(\mathrm{mmHg})\end{array}$ & Mean (SD) & $142(22.2)$ & $135.5(19)$ & $135(16.5)$ & $134.1(16.8)$ & $138.1(19)$ & $132.5(17.3)$ & $138.2(16.7)$ & $134.5(14.4)$ \\
\hline $\begin{array}{l}\text { Diastolic } \\
\text { blood } \\
\text { pressure } \\
(\mathrm{mmHg})\end{array}$ & Mean (SD) & $76.9(10.1)$ & $75.2(9.1)$ & $76.2(10.5)$ & $72.5(8.8)$ & $73.9(11)$ & $74(9.7)$ & $76(9.1)$ & $74.1(9.4)$ \\
\hline
\end{tabular}

CT1, former RCT Control group receiving 1 serving of WP-MND during OLE; CT2, former RCT Control group receiving 2 servings of WPMND during OLE; TT1, former RCT Test group receiving 1 serving of WP-MND during OLE; TT2, former RCT Test group receiving 2 servings of WP-MND during OLE

${ }^{*}$ Significant difference between TT1 and TT2; $p$ value $=0.018(t$ test $)$

Table 5 Incidence of the gastrointestinal symptoms at baseline of the RCT study (week 0 ) and at the end of the RCT (week 13) in the test and the control group

\begin{tabular}{|c|c|c|c|c|c|}
\hline \multirow[t]{2}{*}{ GI symptoms } & \multirow[t]{2}{*}{ Statistic } & \multicolumn{2}{|c|}{ Week 0 (baseline RCT) } & \multicolumn{2}{|c|}{$\begin{array}{l}\text { Week } 13 \text { (end RCT, baseline } \\
\text { OLE) }\end{array}$} \\
\hline & & Control $(n=195)$ & Test $(n=184)$ & Control $(n=195)$ & Test $(n=184)$ \\
\hline Nausea & $n(\%)$ & $21(10.8 \%)$ & $14(7.6 \%)$ & $15(9.5 \%)$ & 17 (11.9\%) \\
\hline Belching & $n(\%)$ & $48(24.6 \%)$ & $44(23.9 \%)$ & $36(22.8 \%)$ & $36(25.2 \%)$ \\
\hline Feeling of fullness & $n(\%)$ & $44(22.6 \%)$ & $39(21.2 \%)$ & $49(31.0 \%)$ & $48(33.6 \%)$ \\
\hline Vomiting & $n(\%)$ & $4(2.1 \%)$ & $4(2.2 \%)$ & $3(1.9 \%)$ & $1(0.7 \%)$ \\
\hline Abdominal distension & $n(\%)$ & $46(23.6 \%)$ & $45(24.5 \%)$ & $33(20.9 \%)$ & $29(20.3 \%)$ \\
\hline Flatulence & $n(\%)$ & $78(40 \%)$ & $82(44.6 \%)$ & $46(29.1 \%)$ & $54(37.8 \%)$ \\
\hline Diarrhoea & $n(\%)$ & $20(10.3 \%)$ & $19(10.3 \%)$ & $20(12.7 \%)$ & $15(10.6 \%)$ \\
\hline Constipation & $n(\%)$ & $48(24.6 \%)$ & $60(32.6 \%)$ & $28(17.7 \%)$ & $36(25.2 \%)$ \\
\hline Dry mouth & $n(\%)$ & $71(36.9 \%)$ & $80(43.5 \%)$ & $53(33.5 \%)$ & $53(37.1 \%)$ \\
\hline Thirst & $n(\%)$ & $34(17.4 \%)$ & $39(21.2 \%)$ & $29(18.4 \%)$ & $40(28 \%)$ \\
\hline
\end{tabular}

CT1, former RCT Control group receiving 1 serving of WP-MND during OLE; CT2, former RCT Control group receiving 2 servings of WP-MND during OLE; TT1, former RCT Test group receiving 1 serving of WP-MND during OLE; TT2, former RCT Test group receiving 2 servings of WP-MND during OLE 


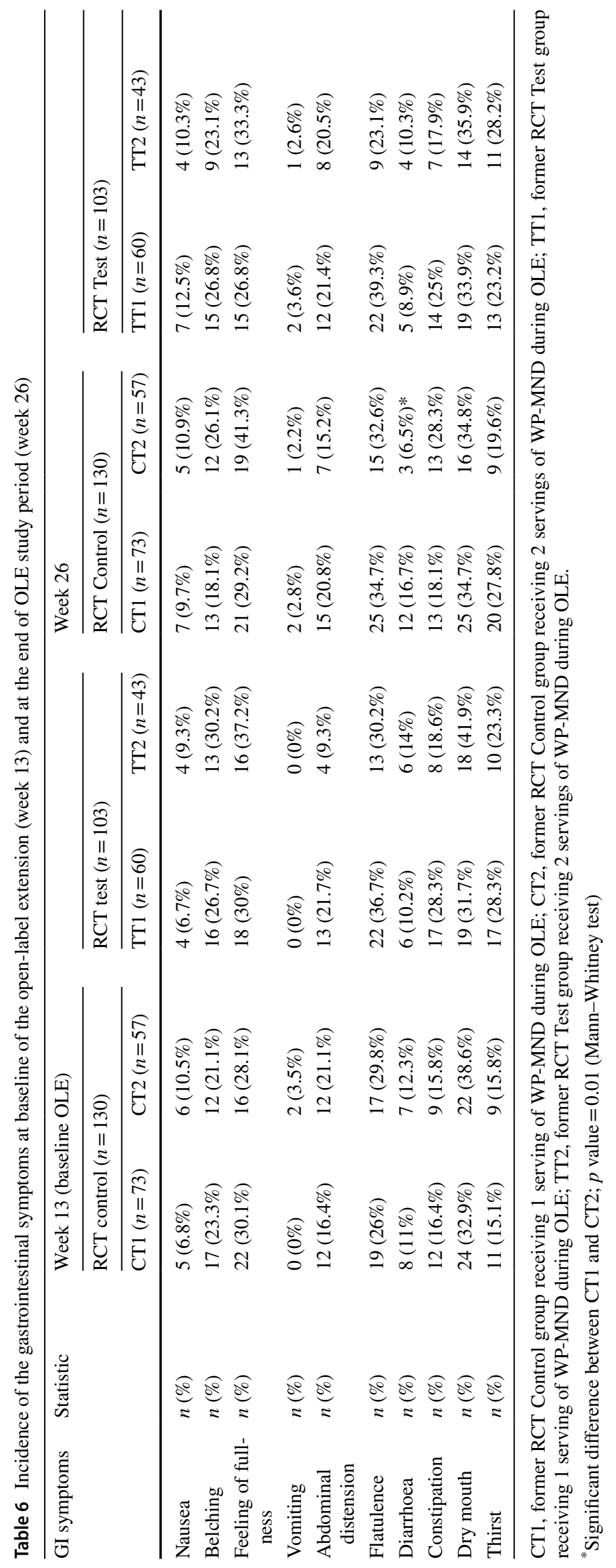




\section{References}

1. Chanet A, Salles J, Guillet C et al (2017) Vitamin D supplementation restores the blunted muscle protein synthesis response in deficient old rats through an impact on ectopic fat deposition. $\mathrm{J}$ Nutr Biochem 46:30-38

2. Salles J, Chanet A, Giraudet C et al (2013) 1, $25(\mathrm{OH})$ 2-vitamin D3 enhances the stimulating effect of leucine and insulin on protein synthesis rate through Akt/PKB and mTOR mediated pathways in murine $\mathrm{C} 2 \mathrm{C} 12$ skeletal myotubes. Mol Nutr Food Res 57:2137-2146

3. Ceglia L, Niramitmahapanya S, da Silva MM et al (2013) A randomized study on the effect of vitamin $\mathrm{D}(3)$ supplementation on skeletal muscle morphology and vitamin D receptor concentration in older women. J Clin Endocrinol Metab 98:E1927-E1935

4. Visser M, Deeg DJ, Lips P et al (2003) Low vitamin D and high parathyroid hormone levels as determinants of loss of muscle strength and muscle mass (sarcopenia): the Longitudinal Aging Study Amsterdam. J Clin Endocrinol Metab 88:5766-5772

5. Ross AC, Manson JE, Abrams SA et al (2011) The 2011 report on dietary reference intakes for calcium and vitamin $\mathrm{D}$ from the Institute of Medicine: what clinicians need to know. J Clin Endocrinol Metab 96:53-58

6. Cruz-Jentoft AJ, Kiesswetter E, Drey M et al (2017) Nutrition, frailty, and sarcopenia. Aging Clin Exp Res 29:43-48

7. Rizzoli R, Stevenson JC, Bauer JM et al (2014) The role of dietary protein and vitamin D in maintaining musculoskeletal health in postmenopausal women: a consensus statement from the European Society for Clinical and Economic Aspects of Osteoporosis and Osteoarthritis (ESCEO). Maturitas 79:122-132

8. De Rui M, Inelmen EM, Pigozzo S et al (2019) Dietary strategies for mitigating osteosarcopenia in older adults: a narrative review. Aging Clin Exp Res 31:897-903

9. Bauer J, Biolo G, Cederholm T et al (2013) Evidence-based recommendations for optimal dietary protein intake in older people: a position paper from the PROT-AGE Study Group. J Am Med Direct Assoc 14:542-559

10. Graafmans W, Ooms M, Hofstee H et al (1996) Falls in the elderly: a prospective study of risk factors and risk profiles. Am J Epidemiol 143:1129-1136

11. Dretakis K, Igoumenou VG (2019) The role of parathyroid hormone $(\mathrm{PTH})$ and vitamin $\mathrm{D}$ in falls and hip fracture type. Aging Clin Exp Res 31:1501-1507

12. Deutz NE, Bauer JM, Barazzoni R et al (2014) Protein intake and exercise for optimal muscle function with aging: recommendations from the ESPEN Expert Group. Clin Nutr 33:929-936

13. Bischoff-Ferrari HA (2012) Vitamin D and fracture prevention. Rheum Dis Clin North Am 38:107-113

14. Bischoff-Ferrari HA, Willett WC, Orav EJ et al (2012) A pooled analysis of vitamin D dose requirements for fracture prevention. N Engl J Med 367:40-49

15. Nutrition EPoDP, Allergies (2016) Dietary reference values for vitamin D. EFSA J 2016:14

16. Ter Borg S, Verlaan S, Mijnarends DM et al (2015) Macronutrient intake and inadequacies of community-dwelling older adults, a systematic review. Ann Nutr Metab 66:242-255

17. Ter Borg S, Verlaan S, Hemsworth J et al (2015) Micronutrient intakes and potential inadequacies of community-dwelling older adults: a systematic review. Br J Nutr 113:1195-1206

18. Vaes AMM, Brouwer-Brolsma EM, Toussaint N et al (2018) The association between 25-hydroxyvitamin D concentration, physical performance and frailty status in older adults. Eur J Nutr 58:1173-1181

19. Bauer JM, Verlaan S, Bautmans I et al (2015) Effects of a vitamin $\mathrm{D}$ and leucine-enriched whey protein nutritional supplement on measures of sarcopenia in older adults, the PROVIDE study: a randomized, double-blind, placebo-controlled trial. J Am Med Dir Assoc 16:740-747

20. Fastbom J, Wills P, Cornelius C et al (1996) Levels of serum creatinine and estimated creatinine clearance over the age of 75: a study of an elderly Swedish population. Arch Gerontol Geriatr 23:179-188

21. Cranney A, Horsley T, O'Donnell S et al (2007) Effectiveness and safety of vitamin D in relation to bone health. Evid Rep Technol Assessment 2007:1

22. Liberman K, Njemini R, Luiking Y et al (2019) Thirteen weeks of supplementation of vitamin D and leucine-enriched whey protein nutritional supplement attenuates chronic low-grade inflammation in sarcopenic older adults: the PROVIDE study. Aging Clin Exp Res 31:845-854

23. Levey AS, Stevens LA, Schmid CH et al (2009) A new equation to estimate glomerular filtration rate. Ann Intern Med 150:604-612

24. Minisola S, Pepe J, Piemonte S et al (2015) The diagnosis and management of hypercalcaemia. BMJ 350:h2723

25. Gallagher JC, Smith LM, Yalamanchili V (2014) Incidence of hypercalciuria and hypercalcemia during vitamin $\mathrm{D}$ and calcium supplementation in older women. Menopause (N Y) 21:1173-1180

26. James MT, Zhang J, Lyon AW et al (2008) Derivation and internal validation of an equation for albumin-adjusted calcium. BMC Clin Pathol 8:12

27. Elliott P, Stamler J, Dyer AR et al (2006) Association between protein intake and blood pressure: the INTERMAP Study. Arch Intern Med 166:79-87

28. Pencharz PB, Elango R, Ball RO (2220S) Determination of the tolerable upper intake level of leucine in adult men. J Nutr 142:2220S-S2224

29. Rasmussen B, Gilbert E, Turki A et al (2016) Determination of the safety of leucine supplementation in healthy elderly men. Amino Acids 48:1707-1716

30. Cynober L, Bier DM, Kadowaki M et al (2249S) A proposal for an upper limit of leucine safe intake in healthy adults. J Nutr 142:2249S-S2250

31. Moller G, Rikardt Andersen J, Ritz C et al (2018) Higher protein intake is not associated with decreased kidney function in prediabetic older adults following a one-year intervention-a preview sub-study. Nutrients 2018:10

32. Marckmann P, Osther P, Pedersen AN et al (2015) High-protein diets and renal health. J Ren Nutr 25:1-5

33. Devries MC, Sithamparapillai A, Brimble KS et al (2018) Changes in kidney function do not differ between healthy adults consuming higher- compared with lower- or normal-protein diets: a systematic review and meta-analysis. J Nutr 148:1760-1775

34. Schwingshackl L, Hoffmann G (2014) Comparison of high vs. normal/low protein diets on renal function in subjects without chronic kidney disease: a systematic review and meta-analysis. PLoS ONE 9:e97656

35. EFSA NDA Panel (EFSA Panel on Dietetic Products Nutrition and Allergies) (2012) Scientific opinion on the tolerable upper intake level of vitamin D. EFSA J 10:2813

36. von Hurst PR, Stonehouse W, Coad J (2010) Vitamin D supplementation reduces insulin resistance in South Asian women living in New Zealand who are insulin resistant and vitamin D deficient - a randomised, placebo-controlled trial. Br J Nutr 103:549-555

37. FNB FNB (1997) Dietary reference intakes for calcium, phosphorus, magnesium, vitamin D and fluoride. Washington DC: Institute of Medicine

38. Stolzenberg-Solomon RZ (2009) Vitamin D and pancreatic cancer. Ann Epidemiol 19:89-95

39. Stolzenberg-Solomon RZ, Hayes RB, Horst RL et al (2009) Serum vitamin $\mathrm{D}$ and risk of pancreatic cancer in the prostate, lung, colorectal, and ovarian screening trial. Cancer Res 69:1439-1447 
40. Holick MF, Chen TC, Lu Z et al (2007) Vitamin D and skin physiology: a D-lightful story. J Bone Miner Res 22:V28-33

41. Klingberg E, Olerod G, Konar J et al (2015) Seasonal variations in serum 25-hydroxy vitamin D levels in a Swedish cohort. Endocrine 49:800-808

42. Tebben PJ, Singh RJ, Kumar R (2016) Vitamin D-mediated hypercalcemia: mechanisms, diagnosis, and treatment. Endocr Rev 37:521-547

43. Frolich A (1998) Prevalence of hypercalcaemia in normal and in hospital populations. Dan Med Bull 45:436-439

44. EFSA NDA Panel (EFSA Panel on Dietetic Products Nutrition and Allergies) (2012) Scientific opinion on the tolerable upper intake level of calcium. EFSA J 10:2814

45. Balage M, Dupont J, Mothe-Satney I et al (2011) Leucine supplementation in rats induced a delay in muscle IR/PI3K signaling pathway associated with overall impaired glucose tolerance. J Nutr Biochem 22:219-226

46. Ter Wee P, Kuhn M, van der Woude H et al (2016) Gastro-Intestinal tolerance and renal safety of protein oral nutritional supplements in nursing home residents: a randomized controlled trial. J Nutr Health Aging 20:944-951

Publisher's Note Springer Nature remains neutral with regard to jurisdictional claims in published maps and institutional affiliations. 